\title{
PROPOSTA DE PROJETO DE UMA EDIFICAÇÃO SUSTENTÁVEL BASEADA NO CONCEITO DE NET ZERO WATER BUILDINGS
}

\author{
DA SILVA Amanda', ARGÔLO Ana Luzia', DO VALE Manuela', OKUMURA Celi', VERÓL Aline ${ }^{3}$ \\ ${ }^{1}$ Graduanda em Arquitetura e Urbanismo, Laboratório de Saneamento e Sistemas Prediais Hidrossanitários da \\ Faculdade de Arquitetura e Urbanismo/UFRJ, Rio de Janeiro, Brasil. \\ ${ }^{2}$ Arquiteta, Programa de Pós Graduação em Arquitetura (PROARQ-FAU/UFRJ), Rio de Janeiro, Brasil. \\ ${ }^{3}$ Doutora em Engenharia Civil, Programa de Pós Graduação em Arquitetura (PROARQ-FAU/UFRJ), Rio de Janeiro, \\ Brasil.
}

Informações do Artigo

Histórico:

Recebimento: 26 Nov 2019

Revisão: 05 Dez 2019

Aprovação: 17 Dez 2019

Palavras-chave:

Net Zero Water Building

Aparelhos economizadores

Reuso de águas cinza
Resumo:

O crescimento das cidades e o aumento da população trouxeram preocupações relacionadas à degradação ambiental e ao eventual esgotamento de recursos naturais. Nessa discussão, insere-se o conceito de Edifícios com Balanço Hídrico Nulo (do inglês, "Net Zero Water Buildings" - NZWB), que maximiza o uso de fontes alternativas de água, minimizando o consumo hídrico e o descarte de águas residuárias para o meio ambiente. Este trabalho tem como objetivo propor um projeto de edificação sustentável, baseada no conceito de NZWB, avaliando o percentual de economia gerada em relação à edificação tradicional. A metodologia de trabalho consiste em resgatar o projeto de edificação multifamiliar de padrão médio, previamente estudado pelos autores; propor a substituição dos aparelhos sanitários tradicionais por aparelhos economizadores; avaliar o percentual de economia que essa mudança produziria; avaliar a possibilidade de implantação de um sistema de reuso de águas cinza e de aproveitamento de águas pluviais, quantificando a vazão do efluente gerado e destacando quais usos poderiam ser cobertos por ele; calcular a economia de água potável considerando a implantação tanto do sistema de captação de água de chuva quanto do tratamento de águas cinza. Os resultados positivos indicam potenciais benefícios econômicos, sociais e ambientais.

\section{Introdução}

O interesse na aplicação de projetos sustentáveis em edificações cresce cada vez mais, considerando o índice de degradação dos recursos naturais, seu desperdício e, consequentemente, a diminuição de sua disponibilidade. Dentro deste discurso, estratégias como as trabalhadas no conceito de Edifícios com Balanço Hídrico Nulo, em inglês Net Zero Water Buildings (NZWB) 
surgem como uma alternativa. A Agência de Proteção Ambiental Americana (Environmental Protection Agency - EPA) define o conceito como um equilíbrio entre demanda e disponibilidade, onde um dado recurso poder ser consumido considerando a sua produção em escala local, independente de abastecimento externo [1]. Assim, visa a preservação da água, a diminuição do uso de energia e a erradicação da produção de resíduos sólidos, contribuindo para a saúde ambiental, promovendo economia, resiliência e sustentabilidade para a sociedade [2].

As Figuras 1 e 2 comparam dois sistemas, o tradicional (Figura 1), onde a água potável suprida pela concessionária vigente abastece o edifício, o efluente gerado (águas cinza e águas negras) é conectado à rede de esgoto, e a água de chuva é direcionada para a rede de drenagem, sem nenhum aproveitamento; e o sistema considerando o conceito de NZWB (Figura 2), onde ocorre o aproveitamento da água de chuva, o reaproveitamento das águas cinza, proveniente de torneiras de lavatórios, tanques, máquinas de lavar roupa e chuveiros, e o tratamento prévio das águas negras.

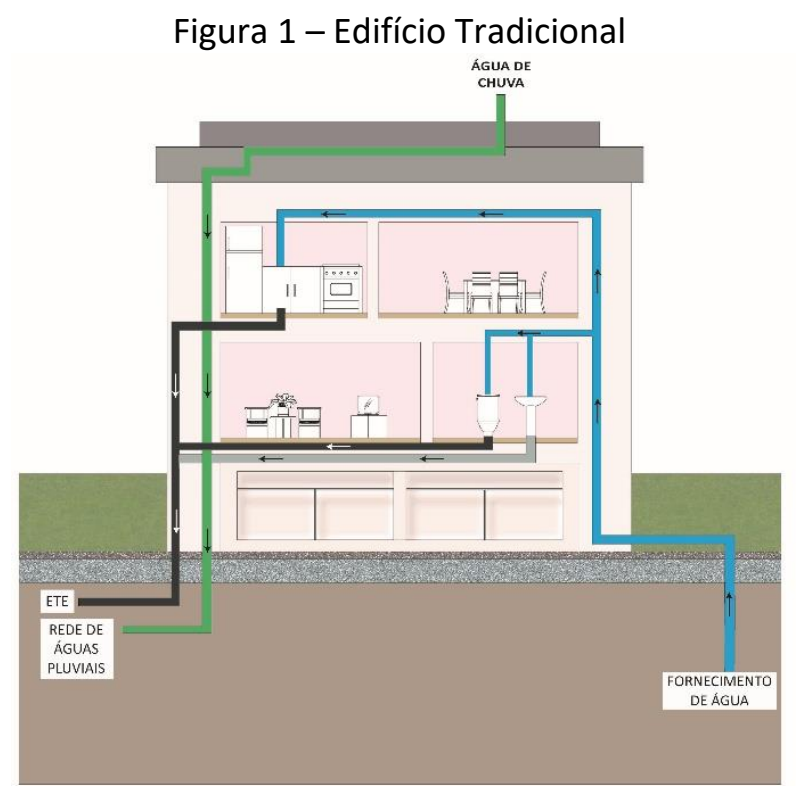

Fonte: Adaptado de SILVA et al. (2019) [3]
Figura 2 - Edifício Net Zero Water Building

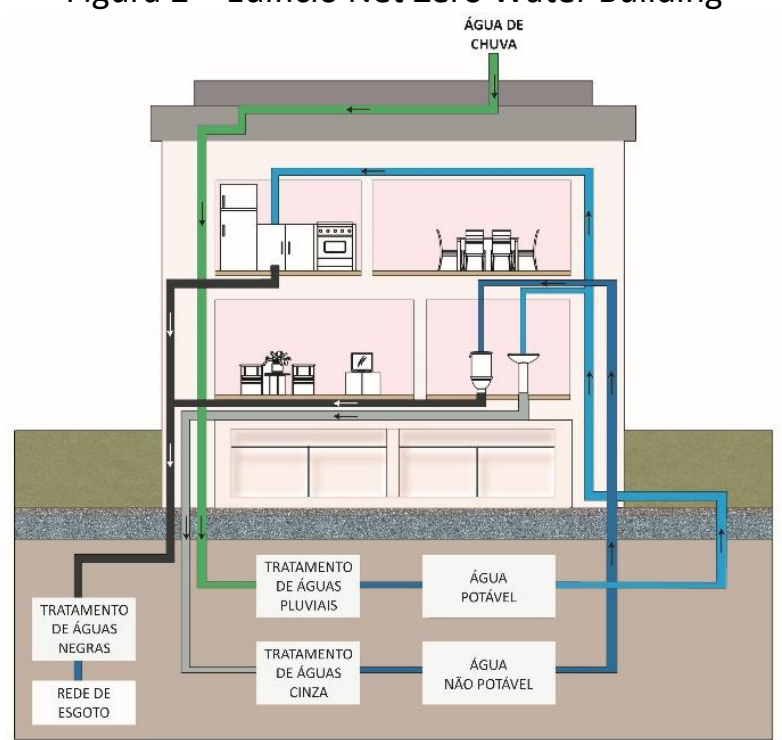

Fonte: Adaptado de SILVA et al. (2019) [3]

Este trabalho tem como objetivo propor um projeto de sistema predial para uma edificação sustentável, baseada no conceito de NZWB, visando um melhor aproveitamento dos recursos hídricos disponíveis, a manutenção dos recursos gastos e a minimização do desperdício. Além disso, avalia-se o percentual de economia gerada em relação a uma edificação tradicional, bem como, calcula-se o tempo de retorno do investimento (payback). Pretende-se definir orientações para a concepção de projetos de arquitetura que levem em conta um projeto de NZWB e que possa ser adaptável a diferentes tipos de edificações.

\section{Metodologia}

O método seguiu as seguintes etapas: 1 . revisão bibliografia sobre NZWB; 2 . resgate da pesquisa de aproveitamento de água pluvial para o projeto de uma edificação multifamiliar de padrão médio, produzida anteriormente pelo grupo; 3 . identificação de possíveis alternativas de consumo por meio de diferentes combinações de uso racional da água; 4. quantificação da vazão do efluente sanitário gerado pelo edifício; 5 . avaliação do percentual de economia de água de cada 
alternativa; 6. realização da estimativa de custo de implantação de cada alternativa; 7 . cálculo do tempo de retorno do investimento (payback) por alternativa.

\section{Resultados e discussão}

\subsection{Apresentação do caso de estudo}

Silva et al. [3] desenvolveram um estudo de aproveitamento de água de chuva baseado em um projeto da NBR 12721:2006 [4], considerando o conceito NZWB. O edifício de médio padrão é composto por 10 pavimentos: pavimento térreo, oito pavimentos tipo e cobertura técnica, totalizando uma área construída de cerca de $6.000 \mathrm{~m}^{2}$. Ele possui 32 unidades habitacionais, compostas por sala, cozinha, área de serviço, 2 banheiros e 2 quartos.

O projeto foi inserido em um terreno de 9500 m2, localizado na Rua Franz Weissman no bairro de Jacarepaguá, Rio de Janeiro. Em virtude da amplitude do terreno e do contexto tipológico local, decidiu-se implantar quatro edifícios, com instalação de um reservatório semienterrado de águas brutas na área central do pavimento térreo reservada para instalação do reservatório semienterrado de águas brutas (Figuras 3 e 4).

Figura 3 - Planta de localização

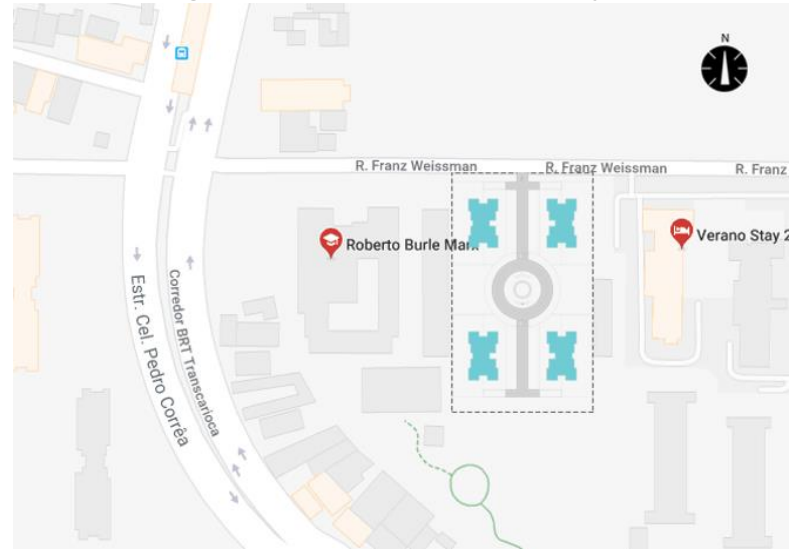

Fonte: SILVA et al. (2019) [3]
Figura 4-3D do conjunto

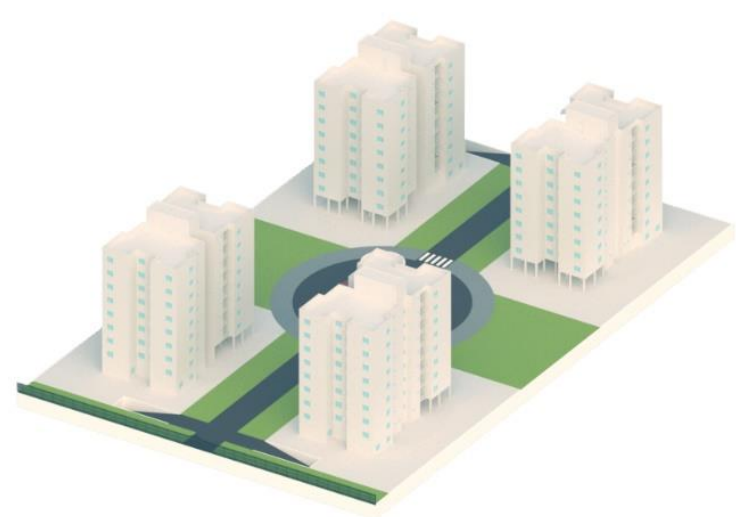

Fonte: SILVA et al. (2019) [3]

\subsection{Alternativas de consumo}

A etapa de estudo das alternativas de consumo caracteriza-se pela análise de diferentes medidas de manejo sustentável da água relacionadas com os usos propostos. Considerando a possibilidade de uso de aparelhos economizadores, da captação de água de chuva e do reuso de águas cinza, foram definidos o reuso da água para fins não potáveis, considerando a legislação vigente, para abastecimento das áreas comuns (irrigação de jardins e lavagem de pisos) e bacias sanitárias. Foram formuladas, então, 8 diferentes alternativas de consumo: 1. Sistema tradicional; 2 . Uso de aparelhos economizadores; 3 . Sistema tradicional com tratamento de efluentes para reuso em áreas comuns; 4. Uso de aparelhos economizadores com tratamento de efluentes para reuso áreas comuns; 5 . Instalação tradicional com tratamento de efluentes para reuso em áreas comuns $e$ bacias sanitárias.; 6 . Uso de aparelhos economizadores com tratamento de efluentes para reuso áreas comuns e bacias sanitárias; 7. Sistema tradicional com aproveitamento de águas pluviais para reuso em áreas comuns; e 8. Uso de aparelhos economizadores com aproveitamento de águas pluviais para reuso em áreas comuns.

Após a definição das alternativas iniciouse o processo de estudo de viabilidade de 
cada uma delas, partindo da estimativa de consumo diário e, posteriormente, mensal que cada uma apresentaria. Em seguida, foi levantada a oferta de água produzida pelos sistemas alternativos de abastecimento de água. As estimativas de consumo para cada opção foram relacionadas com a oferta de água mensal obtida através dos sistemas de captação de água de chuva e/ou reuso de águas cinza e, assim, foi possível analisar a economia que cada uma resultaria.

A estimativa de consumo de água considerou valores de estudos recentes acerca dos hábitos de consumo e densidade populacional dos edifícios no Rio de Janeiro, cujo consumo diário é de 253 litros por habitante [5]. De acordo com o Censo de 2010 [6], a população da cidade do Rio de Janeiro era de 6.320 .446 habitantes, vivendo em 2.083.317 domicílios, o que representa cerca de 3 hab/domicílio. Aplicado ao edifício em questão, isso resulta em um consumo diário de 759 litros por residência e $\mathbf{2 4 . 2 8 8}$ litros por edifício. Assim, mensalmente são consumidos no edifício $728,64 \mathrm{~m}^{3}$ de água. Este valor foi utilizado como referência para as etapas seguintes.

\section{Medidas de conservação da água - 0 projeto}

\subsection{Adoção de aparelhos economizadores}

Com relação às medidas voltadas para a conservação da água, observa-se que a adoção dos aparelhos economizadores se trata da opção que apresenta o menor impacto de implantação, por não modificar os prazos da obra, apenas aumentando o valor do próprio aparelho. Ademais, essa medida é responsável pela redução na fonte do consumo de água potável e, por conseguinte, na redução do efluente gerado.

Para avaliar o potencial de economia de água, foram considerados dispositivos economizadores das marcas Deca e Docol para bacias sanitária, chuveiro, lavatório e pia de cozinha. Considerando dados de vazão e expectativa de consumo em residências citada no PNCDA -DTA-B1 (1998) [7], pode-se estimar a demanda de água que cada dispositivo economizador produziria sobre o consumo diário, bem como, comparar o percentual de redução no consumo em relação aos aparelhos tradicionais, resultando em uma economia de $23 \%$ sobre o consumo total de água. As Figuras 5 e 6 apresentam a compilação dos resultados obtidos quanto ao consumo dos aparelhos sanitários tradicionais e aparelhos sanitários.

Figura 5 - Percentual de consumo com aparelhos tradicionais

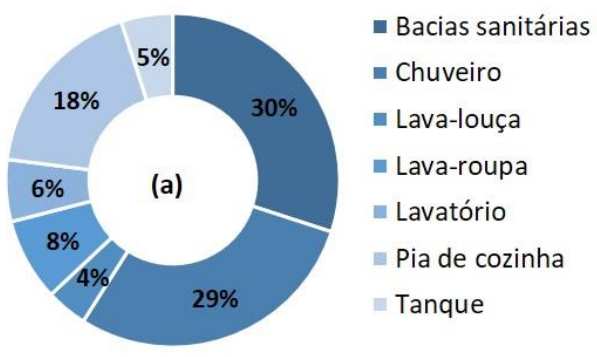

Fonte: Elaborado pelas autoras.

Figura 6 - Percentual de consumo com aparelhos economizadores

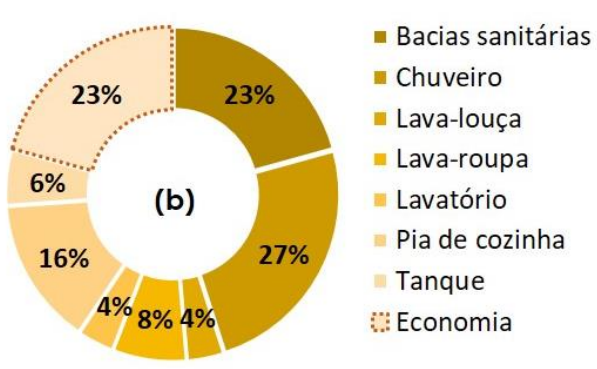

Fonte: Elaborado pelas autoras.

\subsection{Projeto de aproveitamento de águas pluviais}

O projeto de aproveitamento de águas pluviais foi baseado nos usos cobertos pela NBR 15527 [8], tais como: bacias sanitárias, irrigação de jardim, lavagem de veículos, limpeza de pisos, espelhos d'água e usos industriais. A NBR 15527 restringe a área de 
captação apenas às coberturas, ou seja, aos telhados das edificações. A captação oriunda de outras superfícies impermeáveis, como pisos, pode ser reservada para auxílio à drenagem urbana e mitigação de cheias [8].

A chuva captada na cobertura é direcionada para o reservatório semienterrado (RSE), passando antes por uma primeira filtragem (first flush) e pela caixa de areia mais próxima. Do RSE, o volume captado é bombeamento através de um conjunto moto bomba para o reservatório de água tratada, que está elevado no térreo, onde permanecerá armazenada para alimentar quatro pontos de água por meio da própria gravidade. Para a água excedente, os extravasores nos dois reservatórios permitem drenar o volume excedente para as galerias pluviais, auxiliando a diminuição da velocidade do escoamento da água de chuva (Figura 7).

Figura 7 - (a) Perspectiva da implantação dos reservatórios de águas pluviais. (b) 3D do reservatório de águas pluviais

(a)
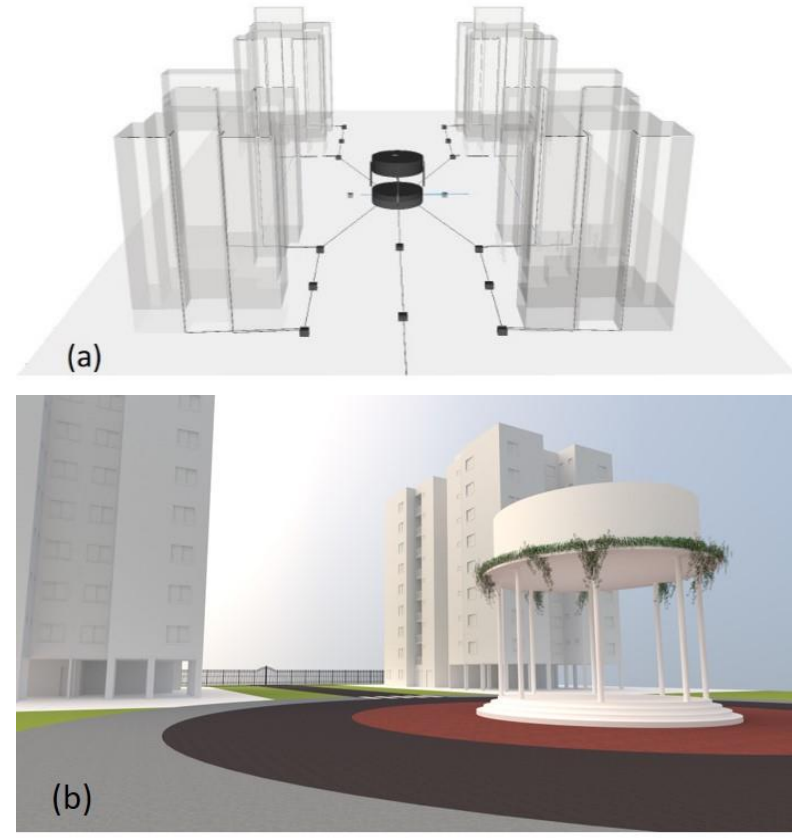

Fonte: SILVA et al. (2019) [3]

Para implantar o sistema de aproveitamento de água de chuva, analisouse a série histórica pluviométrica fornecida pelo Alerta Rio para o local, obtida no posto pluviométrico de Jacarepaguá/Cidade de Deus, localizado na Estrada Mal. Salazar de Moraes, 1409.

\subsection{Projeto de reuso de águas cinza}

Outra medida estudada como forma de promover a economia de água potável foi o reaproveitamento das águas cinza - oriundas de chuveiros, lavatórios, máquinas de lavar roupa e tanques. O desenvolvimento do estudo considerou a NBR 13969 [9].

Para quantificação do efluente gerado pelo edifício, foram adotados valores para a instalação tradicional e com uso de aparelhos economizadores. Considerando-se o consumo de chuveiros, lavatórios, máquinas de lavar roupa e tanques, verificou-se que a instalação tradicional geraria cerca de 350 $\mathrm{m} 3 /$ mês de águas cinza, enquanto a instalação com uso de aparelhos economizadores, 280 m3/mês.

Para implantação do sistema de reúso é necessário que haja a separação entre as águas cinzas dos aparelhos citados dos demais efluentes. Após sua coleta, a água é conduzida a estação de tratamento, onde aplicam-se processos de purificação até que se torne sanitariamente segura. Posteriormente, a água é bombeada para o reservatório e, por fim, abastece os pontos de água para fins não potáveis (Figura 8).

Figura 8-3D esquemático do projeto de reúso de águas cinza

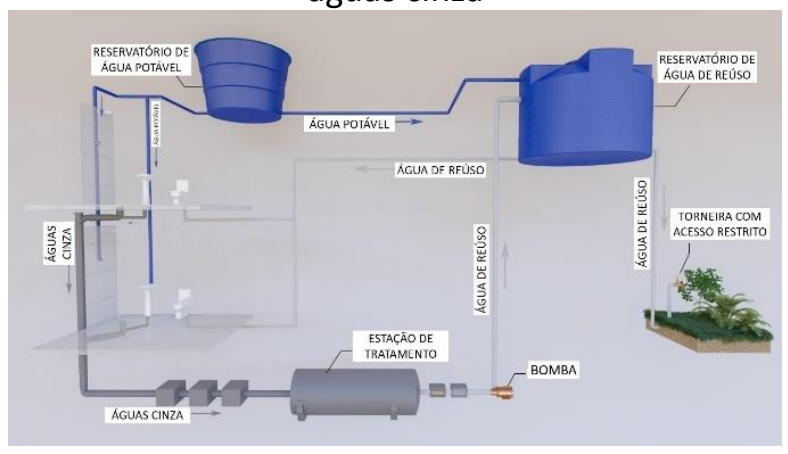

Fonte: Elaborado pelas autoras. 


\subsection{Estudo do consumo mensal de água}

Ao fim da elaboração dos projetos e da determinação dos usos a serem contemplados, foi possível calcular a demanda mensal de água referente a cada alternativa e compará-las com a Alternativa 1. Destaca-se o desempenho da alternativa 6 que utiliza aparelhos economizadores, trata e reutiliza os efluentes (Figura 9).

Figura 9 - Demanda de água gerada por cada alternativa

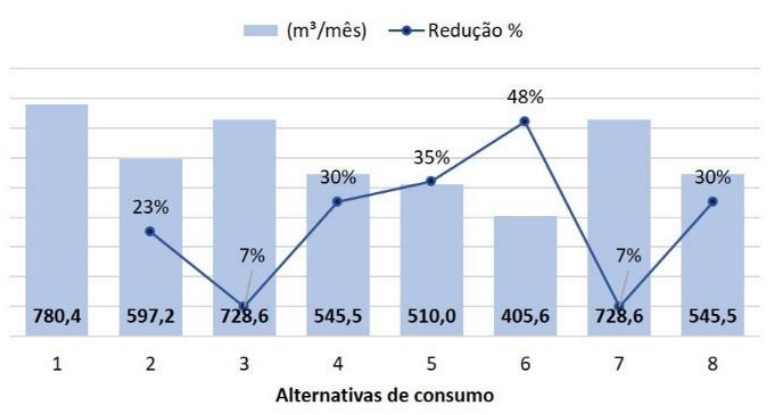

Fonte: Elaborado pelas autoras.

\section{Estudo da viabilidade econômica para implantação das alternativas}

O estudo de viabilidade foi dividido em três etapas: cálculo da tarifa de água, desenvolvimento de orçamento e cálculo do payback de cada alternativa. O primeiro traz a investigação do percentual de economia anual gerado. No orçamento é possível observar quais alternativas demandam mais alterações de projeto, insumos e recursos financeiros. Por fim, o payback demonstra o nível de atratividade econômica que elas podem ter.

\subsection{Cálculo da tarifa de água}

Segundo a Lei no 11.445/2007 [10], são previstas tarifas diferenciadas relativas às categorias dos imóveis e faixas de consumo. Além disso, a CEDAE, concessionária que administra o recurso na cidade do Rio de Janeiro, estabelece tarifas diferentes de acordo com a localidade, seguindo o Decreto no 23.676 de 04 de novembro de 1997 [11]. O cálculo da tarifa é feito sobre a média diária de consumo multiplicada pelo valor da faixa de consumo da categoria. A tarifa domiciliar possui uma tarifa mínima de 0,5 $\mathrm{m}^{3} /$ dia/economia (referente a uma economia [domicílio] por um período de 30 dias), seguida de 5 faixas de consumo: $0-15$; 16-30; $31-45 ; 46-60 ;>60 \mathrm{~m}^{3}$. A cobrança do esgoto é igual à cobrança da água.

Através das estimativas de consumo elaboradas para cada alternativa pode-se calcular o custo de suas respectivas contas de água e avaliar seu percentual de redução em relação ao sistema tradicional de instalação predial. A Figura 10 apresenta os valores estimados das tarifas mensais por tipo de alternativa e o percentual de redução das alternativas 2 a 8 quando comparadas ao valor da tarifa de uma instalação tradicional. Destacam-se as alternativas 4, 5, 6 e 8 com redução superior a $50 \%$.

Figura 10 - Tarifa por alternativa de consumo e percentual de redução

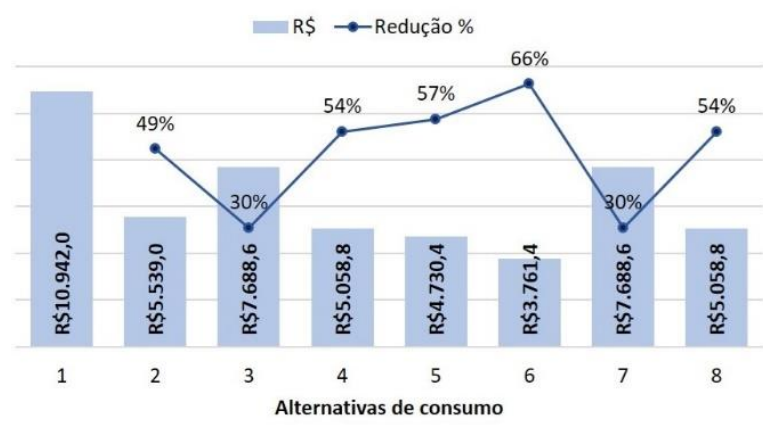

Fonte: Elaborado pelas autoras.

\subsection{Orçamento}

Para a composição do orçamento fez-se a quantificação de todos os insumos e serviços necessários para implantação de cada medida. $O$ estudo considera apenas as quantidades, valores e serviços que excedam ao processo tradicional de obra. No Quadro 1 (Anexo A) são discriminados os serviços empregados e seus respectivos valores. $\mathrm{O}$ orçamento foi elaborado de acordo com a alternativa, observando-se as 
particularidades de cada uma, como demonstrado no Quadro 2 (Anexo A).

\subsection{Payback}

A etapa final do trabalho caracteriza-se pela estimativa do tempo de retorno do investimento relativo à implementação das alternativas. Para esse cálculo foi considerado o valor da implantação sobre a economia anual gerada na conta de água, apresentado no Quadro 2 (Anexo A).

Para validar os valores de payback obtidos no estudo, avaliou-se o trabalho precedente de Ghisi e Ferreira [12], que analisa o potencial de economia de água potável através do emprego dos sistemas de aproveitamento de águas pluviais e reúso de águas cinza em edificação residencial multifamiliar, em Florianópolis/SC, apesar de diferenças em função de localidade e tempo. No entanto, uma série de similaridades o aproxima do presente trabalho, como: a quantidade de áreas molhadas no interior das unidades, a população por apartamento e o número de habitações, que é múltiplo da quantidade de habitações no projeto padrão utilizado no presente estudo. Essas características facilitam a aproximação e comparação dos resultados obtidos. 0 Quadro 3 (Anexo A) apresenta as alternativas relacionadas com $o$ precedente, $e$ as respectivas comparações em função do custo de implantação, economia gerada na conta de água anual decorrente do emprego da medida de conservação e tempo de retorno.

\section{Considerações Finais}

A Legislação Brasileira, referente à qualidade da água, não permite que o conceito de Net Zero Water seja implementado integralmente, de modo a obter autonomia em relação às concessionárias de água. Sendo assim o conceito que melhor se aplica a realidade brasileira é o Nearly Zero Water, no qual o balanço hídrico se aproxima de zero.
Todas as alternativas apresentaram resultados positivos, tanto na economia de água potável quanto na economia sobre a conta de água. Por conseguinte, os resultados de payback também foram favoráveis, o que reforça a alta atratividade para implantação das medidas de conservação. Vale ressaltar que a tarifa cobrada pela concessionária apresenta papel relevante nesse cálculo, portanto, quanto maior, mais rápido o retorno.

A adoção dos aparelhos economizadores apresentou o melhor custo benefício, tendo seu investimento pago em 0,42 anos. Nesse sentido, sugere-se que novos projetos considerem aparelhos sanitários eficientes em suas especificações. O aumento da demanda, incentiva uma produção maior e consequente redução dos custos.

Quanto à adoção da coleta e aproveitamento de águas pluviais, o benefício extrapola o lote, abrangendo o coletivo, a cidade, pois diminui a crescente pressão por aumento de demanda de água potável e contribui para atenuar o escoamento pluvial, mitigando cheias urbanas.

O sistema de reúso de águas cinza apresentou reduções de $54 \%$ a $57 \%$ com aparelhos hidrossanitários tradicionais, e atingiu $66 \%$ quando combinado a aparelhos economizadores. Embora trate-se do sistema pouco explorado e que produz alterações significativas no projeto e na futura rotina de manutenção, sua implantação representa uma redução na demanda de água potável e na geração de efluentes.

Sugere-se, portanto, que novos projetos incorporem práticas que potencializem a economia de água, pois o tempo de retorno do investimento é baixo e os ganhos ambientais, sociais e econômicos altos. 


\section{Referências}

[1] EPA - United States Environmental Protection Agency (2018). Net Zero Concepts and Definitions. Disponível em: $<$ https://www.epa.gov/waterresearch/net-zero-concepts-anddefinitions>. Acesso em: 28 março 2018.

[2] JOUSTRA, C.M., YEH, D.H. Framework for net-zero and net-positive building water cycle management. Building Research and Information, n 43, p. 121-132, 2015.

[3] SILVA, A.O.; ARGÔLO, A.L.L.; MELLO, L.B.M.D.; CUNHA, T.D., FIGUEIREDO, K.; HADDAD, A.N.; MIGUEZ, M.G.; VERÓL, A.P. Aproveitamento de água de chuva em edificações multifamiliares considerando o conceito de Net Zero Water Buildings. EUROELECS, Santa FéParaná, Argentina, 2019.

[4] ASSOCIAÇÃO BRASILEIRA DE NORMAS TÉCNICAS. NBR 12721: Avaliação de custos de construção para incorporação imobiliária e outras disposições para condomínios edilícios. Rio de Janeiro. 2006.

[5] MINISTÉRIO DAS CIDADES. Plano Nacional de Saneamento Básico PLANSAB, Brasília, 2013.

[6] IBGE - INSTITUTO BRASILEIRO DE GEOGRAFIA E ESTATÍSTICA. Censo Demográfico e Contagem Populacional 2010.

[7] PROGRAMA NACIONAL DE COMBATE AO DESPERDÍCIO DE ÁGUA - PNCDA. Documento Técnico de Apoio n. ⒈ Brasília, 1998.

[8] ASSOCIAÇÃO BRASILEIRA DE NORMAS TÉCNICAS. NBR 15527: Água de chuva Aproveitamento de coberturas em áreas urbanas para fins não potáveis Requisitos. Rio de Janeiro. 2007.
[9] ASSOCIAÇÃO BRASILEIRA DE NORMAS TÉCNICAS. NBR 13969: Tanques sépticos - Unidades de tratamento complementar e disposição final dos efluentes líquidos Projeto, construção e operação. Rio de Janeiro. 1997.

[10] BRASIL. Lei no 11.445 de 5 de janeiro de 2007. Estabelece diretrizes nacionais para o saneamento básico. Diário Oficial [da] República Federativa do Brasil, Brasília, DF, 8 jan. 2007.

[11]RIO DE JANEIRO (Estado). Decreto no 23.676 de 04 de novembro de 1997. Altera a estrutura tarifária da companhia estadual de água e esgoto - CEDAE.

[12] GHISI, E.; FERREIRA, D. F. Potential for potable water savings by using rainwater and greywater in a multi-storey residential building in southern Brazil. Building and Environment, v. 42, n. 7, p. 2467-2796, Jul. 2006. 


\section{Anexos e Apêndices}

\section{ANEXO A}

\begin{tabular}{|c|c|}
\hline Serviço & Custo (R\$) \\
\hline 1. Adoção de Aparelhos Economizadores & $13.472,00$ \\
\hline 2. Movimentação de terra p/construção de reservatório & 446,28 \\
\hline 3. Construção de reservatório & $24.244,00$ \\
\hline 4. Rede de captação de efluente & $31.330,97$ \\
\hline 5. Tratamento da água & $6.211,44$ \\
\hline 6. Rede de abastecimento de água tratada no nível térreo & $2.429,22$ \\
\hline 7. Rede de alimentação de bacias sanitárias & $17.691,29$ \\
\hline 8. Sistema de Captação de Água Pluvial & 903,06 \\
\hline
\end{tabular}

Fonte: Elaborado pelas autoras.

* Os valores referentes aos serviços foram retirados de composições do SINAPI.

**Os valores dos aparelhos economizadores foram pesquisados em lojas de construção, adotando-se os de menor custo.

\begin{tabular}{ccccc}
\hline \multicolumn{5}{c}{ Quadro 2-Payback } \\
Alternativa & Serviço empregado & $\begin{array}{c}\text { Custo de } \\
\text { Implantação (R\$) }\end{array}$ & $\begin{array}{c}\text { Economia } \\
\text { anual (R\$) }\end{array}$ & $\begin{array}{c}\text { Tempo de } \\
\text { Retorno (anos) }\end{array}$ \\
\hline 2 & 1 & $13.472,00$ & $66.467,64$ & 0,20 \\
3 & $2,3,4,5,6$ & $64.662,67$ & $29.731,92$ & 2,17 \\
4 & $1,2,3,4,5,6$ & $78.134,67$ & $70.597,56$ & 1,11 \\
5 & $2,3,4,5,6,7$ & $82.353,96$ & $74.538,60$ & 1,10 \\
6 & $1,2,3,4,5,6,7$ & $95.825,96$ & $86.167,32$ & 1,11 \\
7 & $2,3,5,6,8$ & $34.234,77$ & $35.906,52$ & 0,95 \\
8 & $1,2,3,5,6,8$ & $47.706,77$ & $69.172,92$ & 0,69 \\
\hline
\end{tabular}

Fonte: Elaborado pelas autoras.

Quadro 3 - Estudo Comparativo de Payback

\begin{tabular}{cccccc}
\hline $\begin{array}{c}\text { Categoria de } \\
\text { Comparação }\end{array}$ & Alternativa 3 & Alternativa 5 & Precedente (*) & Alternativa 7 & Precedente $\left(^{*}\right)$ \\
\hline $\begin{array}{c}\text { Custo da } \\
\text { implantação }\end{array}$ & $\mathrm{R} \$ 64.662,67$ & $\mathrm{R} \$ 82.353,96$ & $\mathrm{R} \$ 13.121,00$ & $\mathrm{R} \$ 34.234,77$ & $\mathrm{R} \$ 22.900,51$ \\
Economia anual (\%) & $30 \%$ & $57 \%$ & $35 \%$ & $27 \%$ & $31 \%$ \\
Payback & 2,17 anos & 1,1 anos & 2,1 anos & 0,95 anos & 2,4 anos \\
\hline
\end{tabular}

Fonte: Elaborado pelas autoras.

*Os valores obtidos por Ghisi e Ferreira [11] foram atualizados através do INCC - Índice Nacional de Custo da Construção, para valores referentes a agosto de 2019. 